\title{
Monitoring techniques in the capture and adoption of dogs and cats
}

\author{
Jason Onell Ardila Galvis, ${ }^{1}$ Oswaldo Santos Baquero, ${ }^{1,2}$ Ricardo Augusto Dias, ${ }^{1}$ \\ Fernando Ferreira, ${ }^{1}$ Evelyn Nestori Chiozzotto, ${ }^{2}$ José Henrique Hildebrand Grisi-Filho' \\ ${ }^{1}$ Department of Preventive Veterinary Medicine, School of Veterinary Medicine and Animal \\ Science, University of São Paulo, São Paulo; ${ }^{2}$ Zoonosis Control Center, Votorantim City, \\ Brazil
}

\begin{abstract}
The continuous improvement of the information systems of organizations that work toward the control of stray dog and cat populations facilitates the implementation of programmes aimed at reducing the number of animals that roam free in public streets. This study investigated the fate of animals in a Brazilian zoonosis control centre (ZCC) with special reference to euthanasia and adoption. Techniques were applied to visualize the spatial distribution of stray dogs and cats as well as that of the people who adopt these animals. Ripley's K function was used with a Euclidean distance graph to detect the distribution patterns involved. An estimate of the kernel density was used to allow assessment of the spatial distribution of the phenomenon studied. The results show that the distribution of the captured animals, and that of the people who adopted them, form spatial clusters $(\mathrm{P}=0.01)$. Most of the animals were captured near the premises of the ZCC and near the downtown area. Factors such as the abandonment of animals near animal control agencies and the availability of food in these areas could play a role for this outcome. The awareness of the people who live in places where there is a greater number of stray animals and the simultaneous presence of an urban population may explain the concentration of adoptions in these areas. The results may contribute to the implementation of improved measures for the treatment of stray animals.
\end{abstract} \footnotetext{
Paulo, SP, Brazil.

Tel: +55.11.3091.7653 - Fax: +55.11 .3091 .7928 .

E-mail: jason.ardila@usp.br

Received for publication: 26 Februay 2015.

Revision received: 8 April 2015.

Accepted for publication: 13 April 2015.

@C Copyright J.O. Ardila Galvis et al., 2015

Licensee PAGEPress, Italy

Geospatial Health 2015; 10:339

doi:10.4081/gh.2015.339
}

Correspondence: Jason Onell Ardila Galvis, Department of Preventive Veterinary Medicine, School of Veterinary Medicine and Animal Science, University of São Paulo, Av. Prof. Dr. Orlando M. de Paiva 87, 05508270 São

Key words: Stray dog and cat; Public health; Spatial distribution; Brazil.

This article is distributed under the terms of the Creative Commons Attribution Noncommercial License (by-nc 3.0) which permits any noncommercial use, distribution, and reproduction in any medium, provided the original author(s) and source are credited.

\section{Introduction}

Stray dog and cat populations consist of animals not under the control of an owner and which therefore roam free in public spaces. The causes for the abandonment of these animals can be lack of interest, or difficulty in keeping the animal, most likely resulting from a poor choice of a pet or lack of bonding with the animal (Slater et al., 2008). Transmission of zoonoses and aggression towards humans (bites and scratches) are the main public health problems posed by stray animals (Morgan and Palmer, 2007; Sullivan et al., 2008). Most of these animals are controlled through culling. In USA, an estimated 2.4 million dogs and cats are currently killed annually (Patronek et al., 1996) and in Australia, about one-third of dogs entering animal control centres are euthanized (Marston and Bennett, 2005). Although disease control is a strong reason for killing stray animals, this may be ineffective due to rapid replacement with new susceptible animals or other animals from other infected areas as reported with respect to dogs by Courtenay et al. (2002) and Moreira et al. (2004). Thus, new strategies that better control dog and cat populations and do not conflict with the lives of animals must be adopted.

Laws that protect animal life have emerged and gained strength in recent years. In 2008, the State of São Paulo, Brazil, approved law no. 12.916 (State of São Paulo, 2008) that regulates the use of euthanasia of captured dogs and cats. With this new legislation, culling is no longer considered an acceptable control strategy, but reserved for reduction of suffering and to remove aggressive animals, leaving only sterilization and adoption as remaining strategies for stray animal control. Reproductive control (surgical and hormonal) of dog and cat populations is being researched and implemented in all parts of the world with satisfactory results (Wang, 2002; Kutzler and Wood, 2006). In addition, adoption may actually increase the number of sterilizations (Frank and Carlisle-Frank, 2007). Adoption is the main strategy used by animal control centres with the hope of reducing culling of animals. However, these programmes are not as successful as they could be, since they depend on economic status and education level of the surrounding human populations (Weng and Hart, 2012; Peng et al., 2012). Identifying vulnerable human populations and using different approaches to address the issue would be a major advance for animal control organizations that aim at reintegration of caught stray animals into society rather than culling.

The zoonosis control centres (ZCC) in Brazil are departments within municipalities that are responsible, among other activities, for animal control. If these agencies do not manage to get animals adopted, they will run out of space and resources for the receipt of new animals. Therefore, evaluation of the situation is important, and the time trapped animals spend in control centres before adoption is useful in assessing the performance of animal control agencies. Stray animal 
control is difficult because dogs, especially, have a roaming behaviour (Pal et al., 1998) making monitoring complicated due to animal populations that are spread over large areas. Moreover, planning of new strategies is limited by the lack of research and poor information systems. Development of strategies focused on stray dogs and cats requires knowledge of their distribution and behaviour patterns, so improved methodologies to deal with the problem and achieve effective results are needed. Evaluation of the spatial distribution on record at animal control agencies can reveal patterns that would help to understand the dynamics of animal populations as well as human behaviour patterns with regard to abandonment and adoption.

With this study, we aimed to introduce techniques to help agencies to establish control programmes for dogs and cats that can reduce the number of abandoned animals and the number of deaths by culling. The main objective was to present techniques that increase understanding of the spatial distribution of stray animals, and of people who adopt these animals, as well as the fate of these animals (euthanasia, adoption, escape deceased, liberated or otherwise not defined).

\section{Materials and Methods}

The methodologies described here were applied to 361 dog notifications (154 males, 151 females and 7 unknown) and cat captures (19 males, 29 females, 1 unknown) and to 110 animal adoptions (17 cats and 93 dogs). Data were collected from the ZCC in the municipality of Votorantim, São Paulo State, Brazil in the period of 2011-2012. In order to obtain the exact points where animals were captured and where they ended up if/when adopted, addresses obtained from the ZCC database were georeferenced using the website http://www.findlatitudeandlongitude.com/. Maps were produced using the R software (R Core Team, 2013).

Ripley's K function (Ripley, 1977) was used in the spatial pattern analysis to determine if there was a pattern; we were particularly interested in potential cluster tendencies. The $\mathrm{K}$ function is used for a pattern of $X$ stationary points; $\Lambda K(r)$ is defined as the expected number of additional random points within a distance from a typical $X$ random point, where $\Lambda$ is the strengths of the process (density revealed). Thus, the function counts the number of neighbours (in this case captured dogs and cats) within the distance $r$ of each individual. The true value of $K[K(r)=\pi r 2]$ is usually compared with an estimate of $K$ using the difference between the empiric and theoretical $K$ curves, suggesting clustering or spatial regularity. An estimate of $\mathrm{K}$ is derived from a spatial point pattern, which may be used for exploratory analyses. These $\mathrm{K}$ estimates are used to summarize the interaction between the points. The $\mathrm{K}(\mathrm{r})$ estimate is calculated as follows:

$$
R(r)=\frac{a}{n(n-1)} \sum_{i} \sum_{j} I\left(d_{i j} \leq r\right) e_{i j}
$$

where $\alpha$ is the window area and $n$ the number of data points. The sum is taken from all ordered pairs of points $i$ and $j$ in $X, \mathrm{~d}_{\mathrm{ij}}$ is the distance between the two points, while $I\left(d_{i j} \leq r\right)$ is the indicator that is equal to 1 when the distance is less than or equal to $r$. The term $e_{i j}$ is the edge correction weight. The values were computed through 99 simulations $(\mathrm{P}=0.01)$ (Baddeley and Turner, 2005).

A second way to spatially characterize the population of captured dogs was to produce a graph of the Euclidean distance between the cap-



Figure 1. Bar chart of the fate of animals captured by the zoonosis control centre.

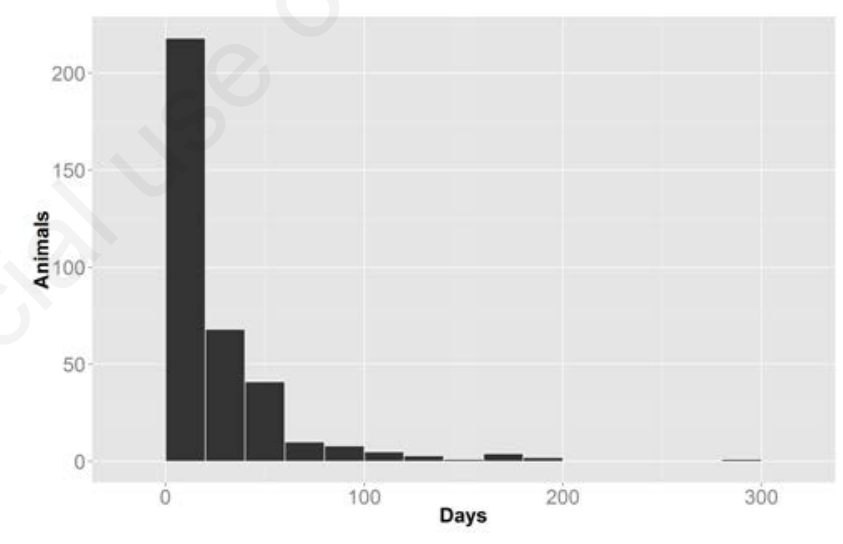

Figure 2. Bar chart showing the time captured animals stayed in the zoonosis control centre before their final fate.

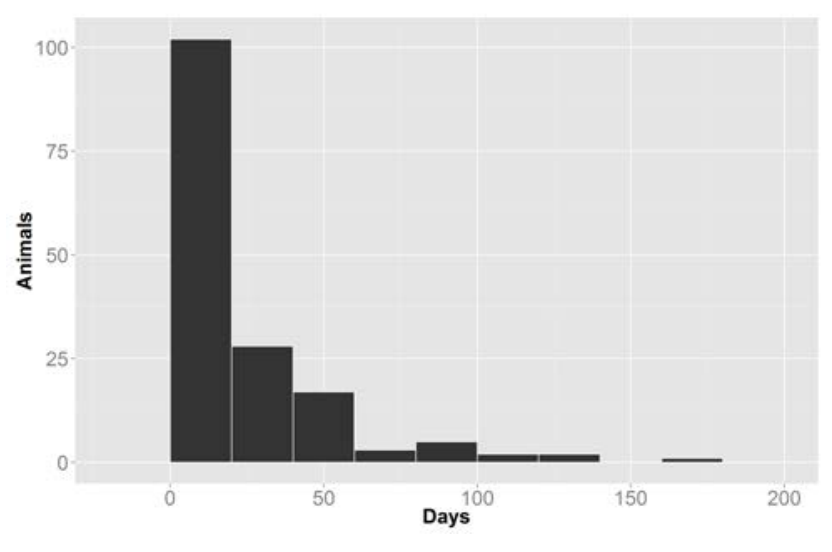

Figure 3. Bar chart depicting the survival time at the zoonosis control centre of animals destined for euthanasia. 


\section{Discussion}

estimated distances to a pattern of points (in this case, the capture site) to a reference point (ZCC in this case), thus evaluating the distance with the higher point density. The capture occurrence density was assessed with an estimated kernel2D density, allowing a better assessment of the spatial distribution of the phenomenon studied. The bandwidth size used in the kernel was $1064 \mathrm{~m}$. For spatial visualization of the events, maps were produced using OpenStreetMaps (www.openstreetmaps.org). All analyses and calculations were made with $\mathrm{R}$ software (R Core Team, 2013) and its spatsat package, version 1.37-0 (Baddeley, 2005), ggplot2, version 1.0.0 (Wickham, 2009) and ggmap, version 1.0.0 (Kahle and Wickham, 2013).

\section{Results}

The main fate of captured animals was euthanasia (44.3\%) and the second was adoption (30.4\%), as specified in Figure 1. The mean residence time of animals in the ZCC was 24 days, and the median was 11 days from the date of capture to the date of its final destination (Figure 2 ). The mean survival time of animals that were euthanized was 20 days, and the median was 9 days from the date of capture to the date of euthanasia (Figure 3). The mean time that adopted animals stayed in the ZCC was 36.72 days, and the median was 25 days (Figure 4), although the calculation could not be performed with 13 animals due to inconsistencies in the database. The residence time for both euthanized and adopted animals seems to follow a power-law with most occurrences in the first days.

The distance between the capture points was strongly clustered (Figure 5) with a high statistical significance $(\mathrm{P}=0.01)$. The kernel density map indicated that the regions with most of the captures were located in the downtown area and around the ZCC building (Figure 6). Indeed, the latter area showed a higher density of captures than the downtown area. The maximum capture density was near the ZCC (Figure 7), which decreased with increasing distance from it $(95 \% \mathrm{CI})$.

As can be seen in Figure 8, the location of the new owners of dogs and cats that were adopted also had a clustered pattern $(\mathrm{P}=0.01)$. The area of greatest concentration of new animal owners was the downtown area, as shown in Figure 9.

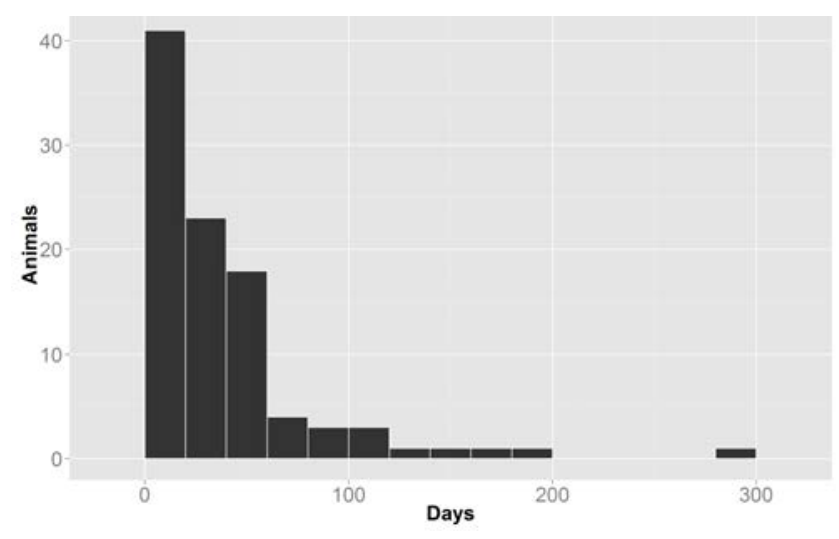

Figure 4. Bar chart depicting the waiting time at the zoonosis control centre of animals destined for adoption.
Knowing the clustered patterns of dog and cat populations is a key factor in developing and implementing measures to control these animals without having to use methods that threaten their lives. Our study provides a view of the spatial distribution of stray dogs and cats between the years 2011 and 2012 in Votorantim municipality in addition to information on the main fates of captured animals.

The capture pattern observed was clearly non-random with statistically significant clustered densities grouped into two regions located in the downtown area and near the ZCC building with the latter point showing the highest concentration of capture events. Various explanations for this distribution include the fact that the capture staff - when venturing outside their premises - could not avoid this area or that people who abandoned dogs and cats did so near the ZCC expecting that the animal would be collected as soon as possible. The second area of great capture density was the downtown area. The high dog and cat population density there might be the cause of this result. The human population density and number of stores and restaurants in the area are, among other factors, potential food sources (Green and Gipson, 1994; Butler et al., 2000), and the concentration of animals is greater in areas where food is available (Dias et al. 2013). Hypothetically, another factor may be the low frequency of garbage disposal and collection and the presence of trash as available food source for stray animals (Beck, 1973).

Most stray dogs are solitary, and the formation of packs is sporadic. The animals rarely show signs of territoriality or fights with other animals, and they can live close to one another (Berman and Dunbar, 1983). Thus, the higher dog density is most likely not a result of the formation of packs. The presence of food and shelter can therefore be a stronger factor in the formation of these clusters. The larger number of animals in these areas increases the probability of disease transmission by increasing contact between the same animals as well as with humans (Rubin and Beck, 1982; Robertson et al., 2000), which seriously affects the quality of life of the diseased animal, other animals and the people who live in the surrounding areas.

A high number of euthanized animals were observed (44\%). Among these animals, many were killed on the first day of capture because they were in a condition of extreme suffering (due to fights, disease,

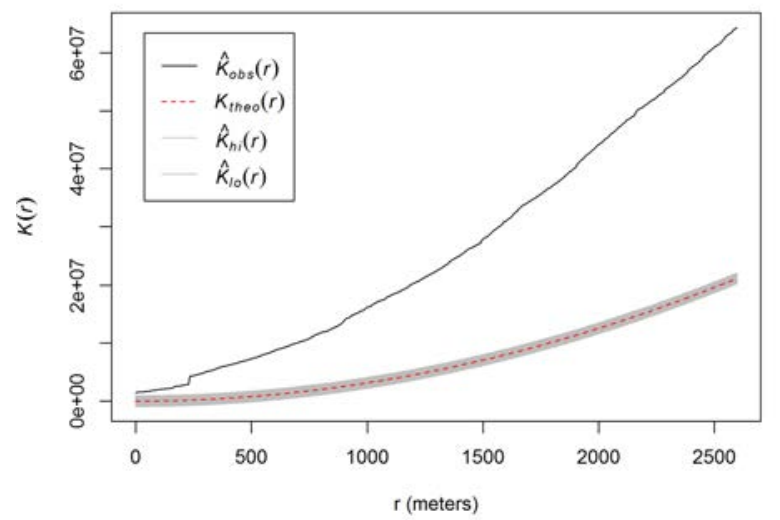

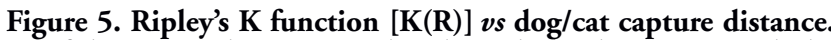
Confidence envelopes (grey band) include the upper and the lower limit of the $K_{\text {theo }}(\mathbf{r})$ (red line) showing a clustering pattern at different distances to compare with the $K_{\text {obs }}(r)$ (black line) after 99 simulations $(P=0.01)$. 
been run over by a car, or for other health-related reasons). The other most frequent fates of animals captured were death due to injury or disease and adoption by locals. The number of adoptions was greater in the first days after the animal was captured, reflecting the campaigns to that effect carried out by the ZCC. The median number of days to adoption (25) reveals a potentially effective adoption campaign, although animals with longer times in residence at the ZCC require specific management. Analyses performed with Ripley's K function, the kernel density map, and the Euclidean distances allowed the detection of spatial patterns of data. These are highly useful tools, and similar



Figure 6. Kernel density map showing the spatial density of captured dogs and cats. High-density areas are shown using blue gradient based on kernel density estimation. Darker areas show a higher concentration of captured animals.

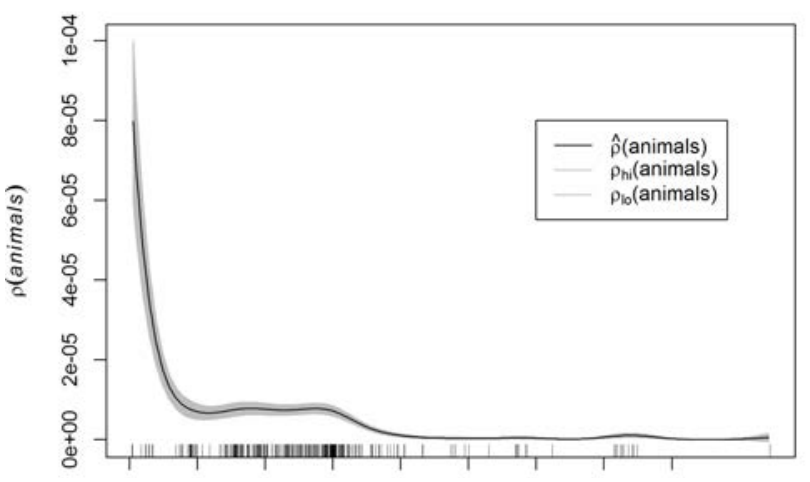

Figure 7. Capture density related to the Euclidean distance between the location of the zoonosis control centre and the point of dog/cat capture. Confidence envelopes (grey band) include the upper and the lower limit of the density of dog and cat capture $[p($ animals $)]$ related to distance. studies using these techniques could provide important results for studying spatial distributions in different populations.

Factors such as perceived low animal age, being sterilized, general health and good behaviour would contribute to people wanting to adopt, given that these factors have been seen as crucial for adoption in other studies (Staats et al., 2010; Fantuzzi et al., 2010; Peng et al, 2012; Weng and Hart, 2012). However, this kind of information was not collected for this study. There were clusters of adoptions in the downtown area. This may have to do with the housing distribution in the city with homes situated far from each other in the suburbs and large urban agglomera-

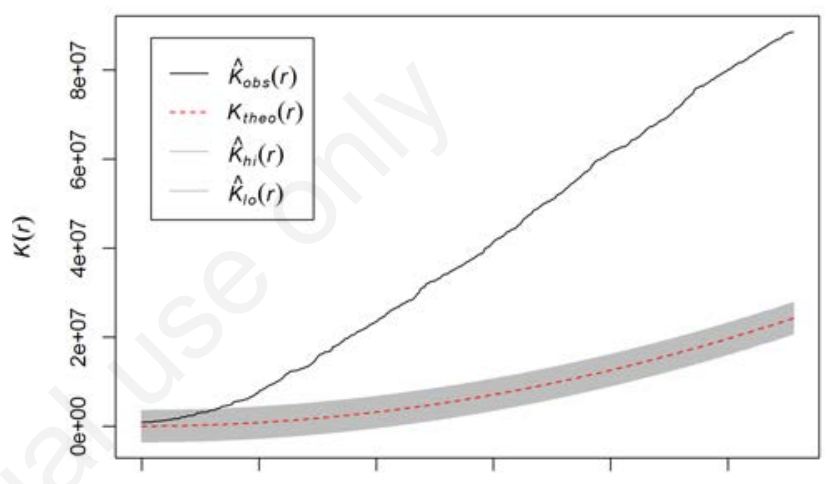

Figure 8. Ripley's K function $[K(r)] v s$ distance (r) for adopted dogs and cats. Confidence envelopes (grey band) include the upper and the lower limit of the $K_{\text {theo }}(r)$ (red line) showing a clustered pattern at different distances compared to the $\mathrm{K}_{\mathrm{obs}}(\mathbf{r})$ (black line) after 99 simulations $(\mathbf{P}=\mathbf{0 . 0 1})$.

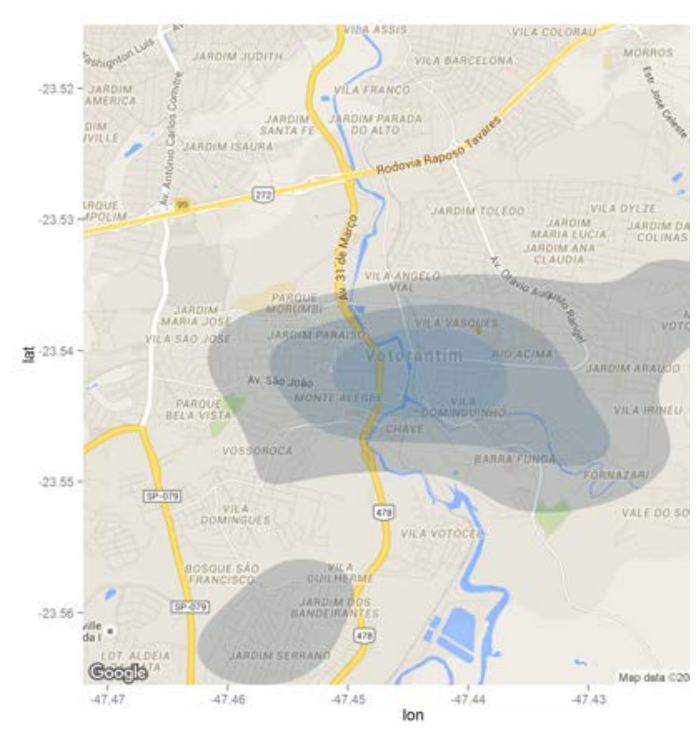

Figure 9. Kernel density map showing the residential location of new owners of dogs and cats that were adopted and taken away from the zoonosis control centre. High-density areas are shown using blue gradient shading based on kernel density estimation. Darker areas show a higher concentration of new homes for adopted animals. 
tion in the downtown area; again circumstances not investigated in detail here. In addition, spatial data can be inaccurate in different ways. Location data can be inaccurate, and the recorded values may be incorrect. Due to the way data were obtained, incomplete or not completed addresses or other such information were the main limiting factors. It is expected that the results of this study will contribute to improving the understanding of the behaviour of stray dogs and cats regarding their spatial distribution, in addition to the behaviour of adopters. With campaigns related to sterilization, vaccinations, education, citizens aim to reduce neglect and abuse and generally understand how to handle dogs and cats correctly. The establishment of new adoption programmes would favour the animals, the ZCC, people who wish to adopt animals and the community in general. Further studies on factors that cause greater intensity of dogs and cats in these areas and studies to estimate the direct and indirect cost of the presence of animals in these areas should be performed.

\section{Conclusions}

The spatial pattern found with respect to the populations of stray dogs and cats in the municipality of Votorantim was strongly clustered with density peaks in the area near the ZCC and the downtown area. Methods visualizing this type of spatial distribution pattern can produce useful results, both when applied to stray animals and to the people who adopt them. The main fates of stray animals are euthanasia and adoption with the downtown area comprising the new homes for most adopted animals. The results presented should enhance control over stray populations of dogs and cats avoiding public health problems and improving the living conditions for stray animals and people living in the city.

\section{References}

Baddeley A, Chang Y-M, Song Y, Turner R, 2012. Nonparametric estimation of the dependence of a point process on spatial covariates. Stat Interface 5:221-36.

Baddeley A, Turner R, 2005. Spatstat: an R package for analyzing spatial point patterns. J Stat Softw 12:1-42.

Beck A, 1973. The ecology of stray dogs: a study of free-ranging urban animals. Purdue University Press, Baltimore, MD, USA.

Berman M, Dunbar I, 1983. The social behaviour of free-ranging suburban dogs. Appl Anim Ethol 10:5-17.

Butler JRA, Toit du JT, Bingham J, 2000. Free-ranging domestic dogs (Canis familiaris) as predators and prey in rural Zimbabwe: threats of competition and disease to large wild carnivores. Biol Conserv 115:369-78.

Courtenay 0, Quinnell RJ, Garcez LM, Shaw JJ, Dye C, 2002. Infectiousness in a cohort of Brazilian dogs: why culling fails to control visceral leishmaniasis in areas of high trans $\neg$ mission. J Infect Dis 186:1314-20.

Dias RA, Guilloux AGA, Borba MR, Guarnieri MCDL, Prist R, Ferreira F, Stevenson M, 2013. Size and spatial distribution of stray dog population in the University of São Paulo campus, Brazil. Prev Vet Med 110:263-73.

Fantuzzi JM, Miller K, Weiss E, 2010. Factors relevant to adoption of cats in an animal shelter. J Appl Anim Welf Sci 13:174-9.

Frank JM, Carlisle-Frank PL, 2007. Analysis of programs to reduce overpop- ulation of companion animals: do adoption and low-cost spay/neuter programs merely cause substitution of sources? Ecol Econ 62:740-6.

Green JS, Gipson PS, 1994. Feral dogs. In: Hygnstrom SE, Timm RM, Larson GE, eds. The handbook: prevention and control of wildlife damage. University of Nebraska, Lincoln, NE, USA, pp 77-82. Available from: http:/digitalcommons.unl.edu/icwdmhandbook/35/

Kahle D, Wickham H, 2013. ggmap: a package for spatial visualization with Google Maps and OpenStreetMap. R package version 2.3. Available from: http//CRAN.R-project.org/package=ggmap

Kutzler M, Wood A, 2006. Non-surgical methods of contraception and sterilization. Theriogeonology 66:514-25.

Marston L, Bennett P, 2005. What happens to shelter dogs? Part 2. Comparing three Melbourne welfare shelters for nonhuman animals. J Appl Anim Welf Sci 8:25-45.

Moreira ED, Mendez de Souza VM, Sreenivasan M, Nacimiento EG, Pontes de Carvalho L, 2004. Assessment of an optimized dog-culling program in the dynamics of canine Leishmania transmission. Vet Parasitol 122:245-52.

Morgan M, Palmer J, 2007. Dog bites. Brit Med J 334:413-7.

Pal S, Ghosh B, Roy S, 1998. Dispersal behaviour of free-ranging dogs (Canis familiaris) in relation to age, sex, season and dispersal distance. Appl Anim Behav Sci 61:123-32.

Patronek GJ, Glickman LT, Beck AM, McCabe GP, Ecker C, 1996. Risk factors for relinquishment of dogs to an animal shelter. J Am Vet Med Assoc 209:573-81.

Peng SJ-L, Lee LY-T, Fei AC-Y, 2012. Shelter animal management and trends in Taiwan. J Appl Anim Welf Sci 15:346-57.

$\mathrm{R}$ Core Team, 2013. R: a language and environment for statistical computing. R Foundation for Statistical Computing, Vienna, Austria. Available from: http:/www.R-project.org/

Ripley BD, 1977. Modelling spatial patterns (with discussion). J Roy Stat Soc B 39:172-212.

Robertson ID, Irwin PJ, Lymbery AJ, Thompson RCA, 2000. The role of companion animals in the emergence of parasitic disease. Int J Parasitol 30:1369-77.

Rubin HD, Beck AM, 1982. Ecological behavior of free-ranging urban pet dogs. Appl Anim Ethol 8:161-8.

Slater MR, Di Nardo A, Pediconi 0, Dalla Villa P, Candeloro L, Alessandrini B, Del Papa S, 2008. Free-roaming dogs and cats in central Italy: public perceptions of the problem. Prev Vet Med 84:27-47.

Staats S, Wallace H, Miller D, Anderson T, 2010. Perceived best ages for cats, dogs, and humans: comparisons across species, human age, and human gender. Soc Anim 18:273-90.

State of São Paulo, 2008. Lei $n^{0} 12.916$, de 16 de abril de 2008. Dispõe sobre o controle da reprodução de cães e gatos e dá providências correlatas. Available from: http//www.al.sp.gov.br/norma/?id=76836

Sullivan ENO, Jones BR, Sullivan KO, Hanlon A J 2008. Characteristics of 234 dog bite incidents in Ireland during 2004 and 2005. Vet Rec $163: 37-42$.

Wang M, 2002. Neutersol: intratesticular injection induces sterility in dogs. In: Proc. Int. Symp. on Nonsurgical Methods for Pet Population Control, Callaway Gardens, GA, April 19-21, 2002. Alliance for Contraception for Cats and Dogs, Portland, OR, USA, pp 62-65.

Weng H-Y, Hart L, 2012. Impact of the economic recession on companion animal relinquishment, adoption, and euthanasia: a Chicago animal shelter's experience. J Appl Anim Welf Sci 15:80-90.

Wickham H, 2009. ggplot2: elegant graphics for data analysis. Springer, New York, USA. 